\title{
A RELAÇÃO JURÍDICA MÉDICO E PACIENTE: QUANDO O MÉDICO É RESPONSABILIZADO PELOS SEUS ERROS
}

\begin{abstract}
Resumo: o presente trabalho tem como premissa identificar as possíveis formas de responsabilização civil aplicáveis aos mais variados casos de erro médico, bem como os requisitos indispensáveis à caracterização do devido dever de indenizar pelo profissional da Medicina. Para tanto, utilizou-se do procedimento bibliográfico a fim de examinar os fundamentos teóricos definidos por doutrinas, artigos, jurisprudências e legislação. A pesquisa revelou que a responsabilidade civil do médico será subjetiva quando decorrente de obrigação de meio, tida como regra pela doutrina; e objetiva, quando derivada de obrigação de resultado. Demonstrou ainda que, ao restar comprovada a diligência, prudência e perícia empregada pelo profissional ao caso clínico do paciente, estar-se-á diante de um caso isento de responsabilidade civil; de vez que, quando agir com negligência, imprudência ou imperícia, restará configurado o chamado erro médico culpável, o que possibilitará a indenização decorrente do dano experimentado pela vítima.

Palavras-Chave: Erro médico. Responsabilidade Civil. Obrigação de meio e de resultado. Direito Médico.
\end{abstract}

\section{DOCTOR AND PATIENT'S JURIDICAL RELATIONSHIP: WHEN THE DOCTOR IS HELD RESPONSIBLE FOR THEIR ERRORS}

\begin{abstract}
: this project proposes to identify the possible ways of doctor's civil charging applicable to most variable cases of medical error, as well as the essential requirements to characterize the obligation to indemnify by the medical professionals. Therefore, bibliographic procedure had been used in order to examine the theoric fundamentals defined by doctrines, magazines, articles, journals, jurisprudence and legislation. The research demonstrated that the doctor's civil responsibility will be subjective when resulting from the environment obligation, had as rule by the doctrine; and objective, when derivative of the obligation of outcome. It has also shown that, when proved the diligence, cautiousness and ability performed by the professional taking care of the patient's clinical case, it will be a case immune from civil responsibility; otherwise, when acting with negligence, imprudence or malpractice, it will be set the called blamable medical error, what will enable the indemnity for the victim's experienced damage.
\end{abstract}

Key-Words: Medical error. Civil Responsibility. Environment and Outcome Obligation. Medical Law.

\section{Introdução}

A atividade médica tem como fundamento a preservação da saúde, do bem estar e da vida do paciente. Sendo assim, compete ao profissional da medicina atuar com zelo e prudência no exercício de sua profissão, a fim de diagnosticar, tratar e oportunizar a cura ao paciente.

É fato que o médico não pode assumir a responsabilidade de curar um paciente, já que a cura e a sobrevivência dependem dos mais variados fatores biológicos e comportamentais, peculiares a cada ser humano. Contudo, quando munido de negligência, imprudência ou imperícia vir a causar dano a outrem, será responsabilizado civilmente pelos seus erros, uma vez que restará configurada a culpa profissional.

Cabe registrar, que o instituto da responsabilidade civil deve ser aplicado com cautela, haja vista que um profissional acusado de erro responderá, antes de qualquer coisa, com a sua imagem perante a sociedade que, muitas vezes, por ignorância, não compreende os limites existentes e impostos pela própria Medicina.

Nesse contexto, o presente artigo demonstrará a relação jurídica existente entre o médico e o paciente, os deveres assumidos pelo profissional da medicina e as espécies de obrigações 
médicas que norteiam a atividade, a fim de fundamentar o instituto do erro médico propriamente dito e a consequente forma de responsabilização civil admitida pelo Direito.

\section{Dever Jurídico do Médico}

A atividade médica atual requer transparência na relação médico-paciente, determinando os direitos, os deveres e as reais expectativas acerca de um determinado procedimento; partindo de regras claras, a fim de assegurar tanto ao contratante quanto ao contratado o que fora acordado.

O Código de Ética Médica (2009), instituído pela Resolução do Conselho Federal de Medicina n$^{\circ} 1931 / 2009$, traz em seu rol um artigo de extrema importância no que se refere ao envolvimento médico-paciente. $\mathrm{O}$ artigo 34 impede a omissão do médico frente ao diagnóstico, prognóstico, riscos e objetivos do tratamento destinados ao paciente, ressalvados os casos em que a comunicação direta ao contratante possa provocar-lhe dano. Devendo, nessas ocasiões específicas, haver interlocução informativa do médico para com o representante legal do paciente.

Diante disso, firmadas as relações contratuais, os médicos passam a ser enquadrados no rol dos prestadores de serviços, independentemente de a relação estabelecida ser proveniente de um contrato expresso, ou tácito - como é o caso da responsabilidade civil extracontratual, tal qual, decorre de um dever jurídico violado, isento de previsão contratual.

O dever jurídico do médico tem como fundamentos a diligência, a prudência e a perícia, uma vez que, vindo a causar dano ao paciente, por ação ou omissão, será responsabilizado civilmente e obrigado a indenizá-lo.

Nas palavras de Delton Croce e Delton Croce Júnior:

Se denomina responsabilidade médica, situação jurídica que, de acordo com o Código Civil, gira tanto na órbita contratual como na extracontratual estabelecida entre o facultativo e o cliente, na qual o esculápio assume uma obrigação de meio, e não de resultado, compromissando-se a tratar do enfermo com desvelo ardente, atenção e diligência adequadas, a adverti-lo ou esclarecêlo dos riscos da terapia ou da intervenção cirúrgica propostas e sobre a natureza de certos exames prescritos, pelo que se não conseguir curá-lo, ou ele vier a falecer, isso não significa que deixou de cumprir o contrato (CROCE; CROCE JÚNIOR, 2002, p.3-4).

Desse modo, pode-se dizer que o médico tem como dever a utilização da melhor técnica e diligência para a resolução do caso clínico, levando em conta que não pode ser obrigado a alcançar a cura propriamente dita ou assegurar a sobrevida de um paciente em risco.

Viés em que, reza Marcos Vinicius Coltri: 
Na hipótese de prestação de serviços médicos, o ajuste contratual - vínculo estabelecido entre médicos e paciente - refere-se ao emprego da melhor técnica e diligência entre as possibilidades de que dispõe o profissional, no seu meio de atuação, para auxiliar o paciente. Portanto, não pode o médico assumir compromisso com um resultado específico, fato que leva ao entendimento de que, se ocorrer dano ao paciente, deve-se averiguar a culpa do profissional (COLTRI, 2010, p.54).

Assim, sendo o paciente prejudicado patrimonialmente ou moralmente em decorrência do tratamento a que fora submetido ou do diagnóstico que lhe fora informado, estará o médico, mediante apuração da culpa, obrigado a indenizar, uma vez que é dever jurídico dele "usar todos os meios disponíveis de diagnóstico e tratamento, cientificamente reconhecidos e a seu alcance, em favor do paciente" (CÓDIGO DE ÉTICA MÉDICA, 2009, art.32).

Nesse contexto, "o alvo de toda a atenção do médico é a saúde do ser humano, em benefício da qual deverá agir com o máximo de zelo e o melhor de sua capacidade profissional", buscando aprimorar continuamente seus conhecimentos e usufruir das melhores técnicas ofertadas pela ciência em benefício do paciente (CÓDIGO DE ÉTICA MÉDICA, 2009, Capítulo I - PRINCÍPIOS FUNDAMENTAIS, Incisos II e V), “principalmente na área do diagnóstico que passa por transformações constantes devido ao desenvolvimento de novas tecnologias" (SCHAEFER, 2012, p.35).

\section{Obrigação de meio e de resultado}

As obrigações provenientes dos contratos firmados entre médicos e pacientes podem ser de meio ou de resultado. Sendo de meio, aquelas sobre as quais o médico tem por obrigação a utilização de todos os métodos e recursos para que ocorra a melhor condução do caso clínico apresentado, fazendo-se irrelevante a verificação do resultado; e de resultado, aquelas, onde os meios não importam, tendo relevância, apenas os resultados obtidos (SCHAEFER, 2012, p.38).

O médico, ao assistir o cliente, assume, em regra, a obrigação de meio, devendo apenas esforçar-se para obter a cura do paciente, mesmo que não a consiga (KFOURI NETO, 2013, p.84), de forma que, empregando toda a diligência e conhecimento técnico que possui, atue em consonância com os princípios éticos e morais (GIOSTRI, 2009, p.76).

Segundo Sergio Cavalieri Filho (2012), nenhum médico, por maior competência que destine à profissão, pode assumir a obrigação de salvar ou de curar o doente, principalmente quando em estado grave ou terminal, levando em conta que a ciência médica, mesmo com todo seu desenvolvimento na atualidade, é muito limitada. Contexto em que a obrigação assumida pelo médico deverá proporcionar ao paciente todo cuidado, atenção e diligência, não havendo 
que falar em inadimplemento contratual pelo simples fato de o tratamento prescrito não surtir o efeito esperado (CAVALIERI FILHO, 2012, p. 403-404).

Caso típico dessa obrigação é quando o médico utiliza-se de todo o seu conhecimento técnico para tratar a doença de seu paciente, como por exemplo, do câncer. Essa doença, por ser muito grave, depende de tratamento muito profundo e, por vezes, agressivo. Logo, a quimioterapia é um dos tratamentos mais utilizado pelos médicos. No entanto, esse tratamento causa diversos efeitos colaterais, como a perda de cabelos, resistência imunológica muito baixa, que pode provocar outras doenças (IGNÁCIO, 2003, p.63).

Outra situação prática, que vale ser mencionada, é o erro de diagnóstico, que não pressupondo culpa no agir do médico ao atender o paciente, exige que este tenha agido com negligência, imprudência ou imperícia a fim de ser responsabilizado. Como bem descreve Marco Fridolin Sommer Santos:

A não-obtenção do diagnóstico correto apenas demonstra que o resultado esperado não foi alcançado. Mas se o profissional, na busca do diagnóstico utilizou-se corretamente de todos os meios que o estado da técnica e as condições de trabalho the proporcionam, não há que se falar em culpa profissional. O objeto da obrigação, que é a prestação de serviços médicos, não se confunde com a sua finalidade. O fim é a obtenção de um resultado correto. A não-obtenção do resultado esperado não se confunde com a violação da obrigação (SANTOS, 1999, p.83).

Em que pese, tratando-se de obrigação de meio, não caberá ao médico atingir o resultado, mas sim, vestir-se de diligência e prudência para o procedimento que se comprometeu (GIOSTRI, 2009, p.75). Cabendo ao paciente, quando sentir-se lesado, comprovar que o profissional, revestido de negligência, imprudência ou imperícia, causou dano a ele (SCHAEFER, 2012, p.38).

O Código de Defesa do Consumidor (1990) em seu artigo 14, $\S 4^{\circ}$ prevê, de forma expressa, a responsabilidade do profissional liberal, que apurada mediante a verificação da culpa, é considerada subjetiva.

Desse modo, sendo os Tribunais rígidos na exigência da prova, só admitem responsabilização civil médica quando demonstrado o erro grosseiro no diagnóstico, na medicação ministrada, no tratamento desenvolvido, ou ainda na injustificável omissão na assistência e cuidados com o doente (CAVALIERI FILHO, 2012, p.405).

Contudo, a responsabilidade do médico pode ser enquadrada também na obrigação de resultado, uma vez que, por ocasiões especiais, poderá ser decorrente de um acordo de vontade firmado entre as partes, que claramente ilustrado pelas cirurgias estéticas, obriga o profissional, diante de um resultado preestabelecido, a alcançá-lo (GIOSTRI, 2009, p.93). 
Nesse viés, a obrigação do médico pode ser de meio, como geralmente ocorre, mas também de resultado, "como quando faz um Raio X, um checkup, aplica ondas de calor, dá uma injeção, faz transfusão de sangue, procede a determinada esterilização necessária", ou realiza exames laboratoriais, assumindo de forma objetiva a garantia da cura (STOCO, 2011, p.629).

Acerca dos exames laboratoriais e o consequente erro no diagnóstico, faz-se mister mencionar o posicionamento jurisprudencial devidamente representado pela ementa que vem citada a seguir:

RESPONSABILIDADE CIVIL. AGRAVO REGIMENTAL NO RECURSO ESPECIAL. EXAME MÉDICO. BIÓPSIA. FALSO DIAGNÓSTICO NEGATIVO DE CÂNCER. OBRIGAÇÃO DE RESULTADO. RESPONSABILIDADE OBJETIVA.DANO MORAL E DANO ESTÉTICO. CUMULAÇÃO. POSSIBILIDADE. SÚMULA 387/STJ. DECISÃO AGRAVADA, QUE SE MANTÉM POR SEUS PRÓPRIOS FUNDAMENTOS.

1. Na espécie, narram as decisões recorridas que a emissão de resultadonegativo de câncer, quando, na verdade, o diagnóstico era positivo, retardou de tal forma o tratamento que culminou, quando finalmente descoberto, em intervenção cirúrgica drástica provocando defeito na face, com queda dos dentes e distúrbios na fala; contudo, não a tempo suficiente a fim de evitar o sofrimento e o óbito do paciente.

2. Este Tribunal Superior já se manifestou no sentido de que configura obrigação de resultado, a implicar responsabilidade objetiva, o diagnóstico fornecido por exame médico. Precedentes.

3. No caso, o Tribunal de origem, com base no acervo fático-probatório dos autos, de forma bem fundamentada, delineou a configuração dos dois danos - o moral e o estético.

4. Nos termos da jurisprudência deste Tribunal Superior, consolidada na Súmula 387 do STJ, é possível a cumulação de danos morais e estéticos.

5. Nesta feita, a agravante, no arrazoado regimental, não deduz argumentação jurídica nova alguma capaz de alterar a decisão ora agravada, que se mantém, na íntegra, por seus próprios fundamentos.

6. Agravo regimental não provido (AgRg no REsp 1117146/CE. 2009/0008496-

5. Relator: Ministro Raul Araújo. Julgado em: 05/09/2013. Órgão Julgador: Quarta Turma. Publicação: DJe 22/10/2013) (Grifo não original).

Trata-se, pois, de recurso apresentado pelo laboratório emissor do laudo que atestou falso negativo de câncer, causando atraso ao tratamento médico adequado ao caso clínico do paciente.

O paciente, que teve o palato bucal (céu da boca) removido, queda de dentes e distúrbio na voz em função do avançado grau da doença, pugnou indenização pelos danos estéticos e morais experimentados, e o Tribunal, que já havia precedentes manifestos, reconheceu a configuração da obrigação de resultado no caso em tela, a implicar responsabilização civil objetiva do laboratório, delegando desprovimento ao recurso manifesto. 
A responsabilidade médica decorrente de obrigação de resultado, a exemplo das cirurgias estéticas é, na maioria das vezes, analisada de maneira desfavorável ao profissional (KFOURI NETO, 2013, p.200).

Assim, se nas demais especialidades caberá ao profissional atuar com zelo e diligência, munido de meios e técnicas adequadas, na cirurgia plástica, bastará o resultado insatisfatório do paciente para que ocorra o dever de indenizar.

No entanto, Hildegard Taggesell Giostri menciona que, em determinadas situações, não haverá que se falar em responsabilidade do médico em decorrência de obrigação de resultado, a exemplo dos casos em que o paciente desenvolve uma reação anafilática ou é portador de uma enfermidade que nem ele possui conhecimento; ou ainda em complicações provenientes da falta de cuidado do paciente (GIOSTRI, 2009, p.90).

Ademais, na obrigação de resultado, o ônus da prova será invertido, cabendo ao médico provar que não agiu com culpa e que o resultado previamente estabelecido não se concretizou por razões alheias à sua atuação; por força de qualquer causa excludente da responsabilidade civil, a exemplo da culpa exclusiva da vítima (STOCO, 2011, p.629), uma vez que sua culpa será presumida, sendo assim sua responsabilidade, caracterizada como objetiva.

\section{Relação jurídica médico e paciente}

A doutrina divide-se ao tentar classificar a relação jurídica entre médico e paciente. Para alguns doutrinadores, ela é contratual e para outros, extracontratual.

Acerca da responsabilidade civil contratual, Carlos Roberto Gonçalves explana:

Não se pode negar a formação de um autêntico contrato entre o cliente e o médico, quando este o atende. Embora muito já se tenha discutido a esse respeito, hoje já não pairam mais dúvidas a respeito da natureza contratual da responsabilidade médica (GONÇALVES, 1994, p. 255-256).

E Miguel Kfouri Neto, complementa que, independentemente de a responsabilidade civil estar alocada dentre os atos ilícitos, "não mais acende controvérsias caracterizar a responsabilidade civil médica como excontractu” (KFOURI NETO, 2013, p.83).

Desse modo, a natureza contratual da responsabilidade médica é tida hoje como contratual, conforme exposto por José de Aguiar Dias: "ora a natureza contratual da responsabilidade médica não nos parece hoje objeto de dúvida (...). Acreditamos, pois, que a responsabilidade do médico é contratual, não obstante sua colocação no capítulo dos atos ilícitos” (AGUIAR DIAS, 1980, p. 281-282). 
Contudo, embora tida como regra pela doutrina, será extracontratual por exceção quando proveniente de atendimento dispensado a um paciente em estado grave e inconsciente (COUTO FILHO, 2004, p.42).

Viés em que a responsabilidade civil extracontratual ver-se-á caracterizada pelo serviço prestado de maneira espontânea, sem intervenção ou manifestação de vontade do paciente, pelo fato de este estar inconsciente (GIOSTRI, 2009, p.60). É o que ocorre no caso de atendimento à vítima de acidente automobilístico, ou de mal súbito, ocorrido em via pública (LIMA, 2012, p.38).

Em que pese, pouco importa a natureza contratual que vincula o profissional e o seu cliente, seja ela contratual ou extracontratual, tratando-se de uma obrigação de meios, o prejudicado é que tem o dever de apresentar provas que afirmem a violação dessas obrigações (SERPA LOPES, 1995, p.175).

Para tanto, frisa-se que, a modalidade regente da relação vai depender do caso concreto ao qual se submete o médico e o paciente. Sendo indispensável para a configuração da responsabilidade civil contratual, além do contrato propriamente dito, a quebra de uma ou mais cláusulas expressas; e para a responsabilidade civil extracontratual, a violação de um dever jurídico legal.

Ademais, tratando-se da responsabilidade civil contratual e a espécie de contrato por ela acatada, Hildegard Taggesell Giostri (2009, p.59) aponta como adequado o contrato sui generis, qual seja aquele não disciplinado de forma expressa pela lei, mas que permitido, se lícito, em detrimento das mais variadas relações humanas.

Espécie contratual, essa, que difere de todas as demais por ser original, não podendo ser enquadrada em denominações dadas pela lei, uma vez que caberá às partes estabelecer cláusulas que, se em conformidade com a vontade de ambas, far-se-ão prevalecer a autonomia da vontade, desde que observadas as disposições legais, regidas exclusivamente pela prática de atos lícitos, ou cumulada com as normas positivadas no Código de Ética Médica (GIOSTRI, 2009, p.62).

O contrato médico é regido pela confiança que o paciente deposita no profissional, motivo pelo que é caracterizado como intuitu personae, sendo também considerado contínuo, vez que faz-se necessária a existência de lapso temporal entre o diagnóstico, tratamentos e resultados - havendo dever de reparar caso ocorra seu descumprimento (GIOSTRI, 2009, p.63).

É, ainda, um contrato fundamentado na reciprocidade de obrigações, cabendo, de um lado, ao médico dispensar seus cuidados ao paciente; de outro, ao paciente, em regra, remunerar o médico pelo serviço prestado - com exceção, por exemplo, do atendimento realizado pelo 
Sistema Único de Saúde. Ademais, pode ser rescindido a qualquer tempo, desde que não cause prejuízo para qualquer uma das partes (SCHAEFER, 2012, p.39).

Diante do exposto, importa saber que a responsabilização civil independe da circunstância que levou o médico a agir - tendo sido procurado em seu consultório de forma espontânea pela vítima ou tendo agido em uma das situações acima exemplificadas - cabe ao profissional atuar com zelo, em conformidade com os deveres ético-profissionais e morais (GIOSTRI, 2009, p.61), tido que a obrigação de reparação do dano sempre existirá, independente de este ser produzido dentro do contrato ou fora dele (KFOURI NETO, 2013, p.83).

\section{Erro Médico}

Tratando-se do aspecto conceitual norteador do termo "erro médico", pode-se dizer que está intimamente ligado à inobservância técnica do médico para com o caso clínico, de forma que, agindo com negligência, imprudência ou imperícia, possibilite um dano à saúde, ou até mesmo à vida do paciente. (GOMES; FRANÇA, 1998, p.244).

Para que reste configurado o erro médico, deverá ocorrer o confronto entre a conduta médica e o protocolo recomendado pela literatura médica, uma vez que sendo o resultado obtido proveniente de uma técnica semelhante à preconizada nos compêndios, não haverá que se falar em transgressão de normas técnicas; se for diferente, e o mau resultado for decorrente dessa técnica, haverá transgressão (KFOURI NETO, 2013, p.100).

O erro médico pode ser dividido em erro culposo e erro doloso, escusável e inescusável. Sendo culposo aquele praticado pelo agente nas modalidades de negligência, imprudência ou imperícia; e doloso aquele em que o agente pretendeu o resultado (dolo direto) ou assumiu o risco de produzi-lo (dolo indireto). Sendo escusável aquele inevitável, que ocorreria mesmo que o agente tivesse tomado todas as cautelas possíveis; e inescusável aquele que poderia ter sido evitado, caso o agente tivesse tomado todas as cautelas diversas e necessárias antes de agir, sendo assim, evitável (SCHAEFER, 2012, p.61-64).

A culpa traduz a falha pessoal da conduta do agente, uma vez que podendo agir de maneira diversa, em face das circunstâncias específicas do caso, acaba trazendo prejuízos ao paciente. É um juízo sustentado pelo nexo existente entre o fato e a vontade do autor, tal que pode ser manifesto pelo dolo ou pela negligência (ANTUNES VARELA, 1991, p.559).

O erro escusável, também chamado de erro profissional, é caracterizado pela conduta médica correta que, munida de uma técnica incorreta aplicada, propõe falta de diligência ou prudência em razão do que seria esperado de um bom profissional escolhido como padrão.

Acerca do erro escusável, Delton Croce e Delton Croce Júnior justificam que: 
O erro profissional, ou escusável, não é devido à falta de observação das regras e princípios que a Ciência sugere, e sim devido à imperfeição da Medicina arte despida de precisão matemática - e à precariedade dos conhecimentos humanos: há erro escusável, e não imperícia, sempre que o profissional, empregando correta e oportunamente os conhecimentos e regras de sua ciência, chega a uma conclusão falsa, possa, embora, daí, advir um resultado de dano ou de perigo (CROCE; CROCE JÚNIOR, 2002, p.32).

Restando claro que, não havendo culpa, não haverá dever de indenizar pelo profissional, uma vez que:

Culpa e erro profissional são coisas distintas. Há erro profissional quando a conduta médica é a correta, mas a técnica empregada é incorreta; há imperícia quando a técnica é correta, mas a conduta médica é incorreta. A culpa médica supõe uma falta de diligência ou de prudência em relação ao que era esperável de um bom profissional escolhido como padrão; o erro é a falha do homem normal, consequência inelutável da falibilidade humana. E, embora não se possa falar em um direito ao erro, será este escusável quando invencível à mediana cultura médica, tendo em vista as circunstâncias do caso concreto (CAVALIERI FILHO, 2012, p.405).

Todavia, há de levar em conta que o erro médico poderá ser escusável ou não, o que pode, por conseguinte, isentar ou gerar a responsabilidade penal ou civil (CAIXETA, 2003, p.42).

Assim sendo, o erro médico, para ser escusável, deverá estar norteado pelos seguintes elementos:

1. Que o médico assistente não se tenha havido com culpa em qualquer modalidade: negligência, imprudência, imperícia;

2. Que a mal resultância seja consequente a um erro de diagnóstico possível do ponto de vista estatístico;

3. Que no estabelecimento desse diagnóstico tenham oportunamente sido utilizados meios e métodos amiudadamente empregados;

4. Que a terapia clínica e/ou cirúrgica seja habitualmente utilizada para o diagnóstico formulado;

5. Que o evoluir do caso se tenha processado dentro das expectativas (CROCE; CROCE JÚNIOR, 2002, p.33).

Como exemplo de erro profissional escusável, pode ser citado o erro de diagnóstico que, “como regra, não gera responsabilidade, salvo se tomado sem atenção e precauções, conforme o estado da ciência, apresentando-se como erro manifesto e grosseiro" (STOCO, 2007, p.409).

O Código de Ética Médica (2009) em seu artigo $1^{\circ}$ veda, de forma expressa, qualquer forma de dano gerado pelo médico ao paciente, por ação ou omissão, caracterizável como imperícia, imprudência ou negligência. O direito, por sua vez, exige que os profissionais exerçam suas atividades de acordo com os preceitos estabelecidos, com as cautelas e precauções 
necessárias à segurança da vida e da saúde dos clientes e dos fregueses, de tal modo que, agindo desonestamente ou com falta de cuidado, a Lei, repressiva, lhe pune as infrações (BEVILÁQUA, 1930, p.696).

Nesse viés, tendo o médico o dever de agir com diligência e cuidado no exercício de sua profissão, respeitando o estado da ciência e as regras consagradas pela prática médica (AGUIAR JÚNIOR, 2000, p.7), quando age com negligência, imprudência ou imperícia, vê-se diante de um erro passivo de responsabilização em âmbito civil e/ou penal.

Toada em que, decorrentes do erro médico negligente, imprudente ou imperito, os processos ajuizados com a finalidade de obtenção reparatória por danos experimentados aumentaram de maneira significativa nos últimos anos, chegando a atingir o percentual de $140 \%$ entre os anos de 2010 e 2014, no Brasil (CAMBRICOLI, 2015, s/p).

Acerca desse aumento, inclusive, o advogado especialista em Direito Médico, Raul Canal, divulgou recentemente resultados exorbitantes relativos ao aumento de erro médico no Brasil. Munido de dados disponibilizados pelo Superior Tribunal de Justiça, o estudioso publicou no livro Erro médico e Judicialização da Medicina "um aumento de $1.600 \%$ no número de processos judiciais envolvendo médicos, além de um crescimento de $180 \%$ de profissionais condenados nos tribunais de ética dos Conselhos Regionais de Medicina”, entre os anos de 2004 e 2014 (SANTANA, 2014, s/p apud CANAL, 2014).

Não bastasse, revelou que o Paraná, no decorrer dos últimos 13 anos (2001-2014), teve 175 ações em tramitação no TJ-PR, e que no Brasil, 7\% dos médicos respondem a processos em decorrência de erro (SANTANA, 2014, s/p apud CANAL, 2014).

Contexto esse que, diariamente vinculado à mídia, mediante notícias e reportagens, justifica a relevância do assunto escolhido para a elaboração do presente artigo, haja vista a escassa variedade de textos informativos que tratam de maneira direta acerca do erro médico e sua consequente responsabilização civil.

\section{Responsabilidade Civil Subjetiva e/ou Objetiva?}

Inicialmente, faz-se mister frisar que a responsabilidade civil no ordenamento jurídico brasileiro está, intrinsicamente, atrelada à constatação do elemento culpa. Liame em que o conceito norteador da culpa expõe:

A culpa exprime um juízo de reprovabilidade pessoal da conduta do agente: o lesante, em face das circunstâncias específicas do caso, devia e podia ter agido de outro modo. É um juízo que assenta no nexo existente entre o facto e a vontade do autor, e pode revestir duas formas distintas: o dolo (a que os autores 
e as leis dão algumas vezes o nome de má fé) e a negligência ou mera culpa (culpa em sentido estrito) (ANTUNES VARELA, 1991, p.542-543).

Assim, a responsabilidade civil poderá ser subjetiva, quando exigir a verificação da contribuição do comportamento do agente para com o prejuízo experimentado pela vítima; ou objetiva, quando a constatação do elemento culpa for dispensada, vez que esta será presumida, pautada na teoria do risco (KFOURI NETO, 2002, p. 34).

A responsabilidade civil, em regra, é tida como subjetiva pelo Código Civil Brasileiro, visto ter acolhido em seu artigo 186 o dolo e a culpa como fundamentos da obrigação de indenizar; admitindo, apenas em ocasiões específicas, a responsabilização civil objetiva, a exemplo do artigo 927 do Código Civil (2002) que prevê a obrigação de reparação oriunda de dano, "independentemente de culpa, nos casos especificados em lei, ou quando a atividade, normalmente desenvolvida pelo autor do dano, implicar, por sua natureza, risco para os direitos de outrem".

No mais, conforme verificado anteriormente, a obrigação do médico é, em princípio, uma obrigação de meio, onde, tendo o dever de agir com diligência e cuidado no exercício da sua profissão, respeitando as normas e procedimentos instituídos pela ciência, estará isento de culpa e, consequentemente, de responsabilidade civil decorrente, quando não alcançar o resultado esperado pelo paciente.

Nesse viés, a responsabilidade civil do médico será, em regra, subjetiva, uma vez que, amparado pelo artigo 14, $\S 4^{\circ}$ do Código de Defesa do Consumidor (1990) como profissional liberal, responderá mediante comprovação de culpa pela parte consumerista, fundada em ato negligente, imprudente ou imperito (GOMES, 2004, p.50).

Assim, explana Miguel Kfouri Neto:

Evidentemente, a ninguém ocorrerá atribuir aos profissionais da área da saúde o exercício da atividade que, normalmente, por sua própria natureza, implica risco aos direitos do paciente - hipótese que, caso admitida, descartaria a verificação da culpa, na atribuição da responsabilidade, acarretando a adoção da responsabilidade objetiva, fulcrada na teoria do risco criado. Isto porque a atividade curativa, em regra, não gera risco ao paciente. Antes, muito pelo contrário, visa a afastar o risco de agravamento de seu estado de saúde, propiciando melhora ou a cura total. Mesmo que se utilizem equipamentos em procedimentos cirúrgicos (cirurgias videolaparoscópicas, variadas aplicações de laser por exemplo), ainda assim será imperativo provar-se a imperícia, imprudência ou negligência do profissional. Isto porque o advento da nova codificação civil, neste aspecto, nada inovou a responsabilidade médica, em regra, continua a ser subjetiva (KFOURI NETO, 2013, p. 72).

Contudo, embora predominantemente subjetiva, a responsabilidade civil do médico poderá ser, em algumas ocasiões específicas, a exemplo das cirurgias estéticas, objetiva, vez que, 
por tratar-se de uma obrigação de resultado, sugere a presunção de culpa, cabendo a ele provar que não agiu com negligência, imprudência ou imperícia.

É o que alude Maria Helena Diniz ao versar:

O médico que atende a um chamado determina, desde logo, o nascimento de um contrato com o doente ou com a pessoa que o chamou em benefício do enfermo. Há, portanto, um contrato entre o médico e seu cliente, que se apresenta como uma obrigação de meio e não de resultado, por não comportar o dever de curar o paciente, mas sim o de prestar-lhe cuidados conscienciosos e atentos conforme os progressos da medicina, procurando sempre obter seu consentimento prévio e esclarecido. Há casos em que se supõe a obrigação de resultado com sentido de cláusula de incolumidade, como ocorre na cirurgia plástica estética ou no contrato de hospitalização, em que o médico assume o dever de preservar o enfermo de acidentes, hipóteses em que sua responsabilidade civil será objetiva e não subjetiva (DINIZ, 2009, p.265).

E o que entende a jurisprudência, quando em pauta a responsabilização civil decorrente de procedimentos estéticos, observe:

APELAÇÃO CIVEL. RESPONSABILIDADE CIVIL. CIRURGIA PLÁSTICA. RESPONSABILIDADE DE RESULTADO. PROVA PERICIAL. TÉCNICA UTILIZADA INDICADA. Não se conhece do agravo retido interposto quando ausente pedido de apreciação expresso em relação aos fundamentos que pretende ver modificado. Em se tratando de cirurgia estética, a responsabilidade do médico é objetiva. A tarefa médica do cirurgião, portanto, não se caracteriza como obrigação de meio, mas verte obrigação de resultado. Em se tratando de procedimento puramente estético, como na hipótese dos autos, objetivando apenas o embelezamento, o contrato médico-paciente é de resultado, não de meio. A perícia produzida deixou inconteste que o procedimento adotado pelo médico foi o correto. Verifica-se que os réus agiram dentro da conduta coerente e prudente que era esperada, não havendo motivo para ser imputada à responsabilidade que está sendo postulada pela parte autora. AGRAVO RETIDO NÃO CONHECIDO. APELO DESPROVIDO (Apelação Cível No 70036962694, Quinta Câmara Cível, Tribunal de Justiça do RS, Relator: Romeu Marques Ribeiro Filho, Julgado em 23/02/2011) (Grifo não original).

Posto que, a responsabilidade civil do médico será subjetiva quando decorrente de obrigação de meio, tida como regra pela doutrina, e; objetiva quando derivada de obrigação de resultado, vez que previamente estabelecido o resultado objetivado, haverá que considerar a culpa presumida do profissional.

\section{Considerações Finais}

Inicialmente, faz-se mister elencar que nem todas as falhas médicas são passíveis de responsabilização civil, haja vista que muitas vezes o profissional age com a diligência, prudência e perícia esperadas; utiliza todas as técnicas compatíveis com o caso clínico 
apresentado pelo paciente, mas as próprias condições biológicas dele favorecem o insucesso, ou os avanços tecnológicos existentes não são suficientes para o diagnóstico e prognóstico correto do caso.

Nesse viés, sem a pretensão de esgotar o tema, verificou-se que não é propriamente o erro médico que sugere a aplicação do instituto da responsabilidade civil, mas a culpa que, pautada na negligência, imprudência ou imperícia, venha a acarretar dano ao paciente, vez que, tendo o profissional recorrido a todos os meios ofertados pela Medicina a fim de diagnosticar e, consequentemente tratar, estará isento de responsabilização.

Contatou-se que a atividade médica é regida pelo Código de Defesa do Consumidor e que os médicos são enquadrados como profissionais liberais, tais quais respondem pelos seus erros, em regra, mediante a apuração do elemento culpa.

Não bastasse, verificou-se que a obrigação do médico poderá ser uma obrigação de meio ou de resultado: será de meio quando levar em conta apenas os meios utilizados para a obtenção da cura do paciente; de resultado quando, independentemente dos meios utilizados, exigir a obtenção do resultado previamente estabelecido pelas partes.

Acerca da obrigação de meio e de resultado, faz-se pertinente frisar que a obrigação de meio é tida como regra pela doutrina, que nos casos decorrentes deste instituto o profissional da medicina responderá pelos seus erros de maneira subjetiva, ou seja, mediante a comprovação da sua culpa. Doutro modo, tratando-se de um caso decorrente da obrigação de resultado - a exemplo das cirurgias plásticas -, estar-se-á diante de um caso passivo de responsabilização civil objetiva, considerada a culpa profissional presumida configurada.

Podendo-se concluir, contudo, que o reconhecimento do dever de indenizar é o mínimo merecido pela vítima, se analisadas forem as consequências por ela experimentadas, provenientes do erro médico, que, a exemplo dos casos concretos ante analisados, geram danos, algumas vezes, irreversíveis, causadores da limitação do paciente frente a algumas atividades, e até mesmo da morte.

\section{Referências}

AGUIAR DIAS, José de. Cláusula de não-indenizar. 4. ed. Rio de Janeiro: Forense, 1980.

AGUIAR JÚNIOR, Ruy Rosado de. Responsabilidade Civil do Médico. In: Direito e Medicina: aspectos jurídicos da Medicina, Belo Horizonte: Del Rey, 2000. p.133-180. Disponível em: https://www.google.com.br/url?sa=t\&rct=j\&q=\&esrc=s\&source=web\&cd=1\&cad=rja\&uact=8\& ved=0ahUKEwj2tI2d2ZHVAhWDIpAKHQcDCtwQFggnMAA\&url=http\%3A\%2F\%2Fwww.ru yrosado.com.br\%2Fupload\%2Fsite_producaointelectual\%2F23.pdf\&usg=AFQjCNFMTJzpyCW GLcmBwXTOUITFMQooow. Acesso em: 16 ago. 2016. 
ANTUNES VARELA, João de Matos. Das obrigações em geral. 7. ed. Coimbra: Almedina, 1991.

BEVILÁQUA, Clóvis. Código Civil dos Estados Unidos do Brasil Comentado. v. 4. Rio de Janeiro: Francisco Alves, 1930.

BRASIL. Código Civil. Lei Nº10.406 de 10 de janeiro de 2002. Disponível em:

http://www.planalto.gov.br/ccivil_03/leis/2002/L10406.htm. Acesso em: 15 jul. 2015.

Código de Defesa do Consumidor. Lei No8.078 de 11 de setembro de 1990. Disponível em: http://www.planalto.gov.br/ccivil_03/Leis/L8078.htm. Acesso em: 04 ago. 2015

Código de Ética Médica. Resolução do CFM Nº1931/2009. Disponível em:

http://www.portalmedico.org.br/resolucoes/cfm/2009/1931_2009.htm. Acesso em: 03 ago. 2015.

Superior Tribunal de Justiça do Estado do Ceará. AgRg no REsp 1117146/CE. 2009/0008496-5. Relator: Ministro Raul Araújo. Julgado em: 05/09/2013. Órgão Julgador: Quarta Turma. Publicação: DJe 22/10/2013.

Tribunal de Justiça do Rio Grande do Sul. Apelação Cível no 70036962694, Quinta Câmara Cível, Tribunal de Justiça do RS, Relator: Romeu Marques Ribeiro Filho, Julgado em 23/02/2011.

CAIXETA, Francisco Carlos Távora de Albuquerque. Erro médico. Responsabilidade civil médica em cirurgia plástica. 2003. Disponível em: https://pt.scribd.com/doc/19616016/MONOGRAFIA-Direito-Civil-Erro-Medico-

Responsabilidade-Civil-Medica-em-Cirurgia-Plastica-Fr. Acesso em: 16 ago.2016.

CAMBRICOLI, Fabiana. Em 4 anos, número de processos por erro médico cresce $140 \%$ no STJ. Jornal O Estado de São Paulo. Postado em: 22 mar.2015. Disponível em:

http://saude.estadao.com.br/noticias/geral,em-4-anos-numero-de-processos-por-erromedico-cresce-140-no-stj-imp-,1655442. Acesso em: 18 out. 2016.

CAVALIERI FILHO, Sergio. Programa de Responsabilidade Civil. 9. ed. São Paulo: Atlas, 2012.

COLTRI, Marcos Vinicius. Alerta no Centro Cirúrgico. In: Revista Consulex. Ano XIX, $\mathrm{n}^{\circ} 320.15$ de maio de 2010 .

CROCE, Delton; CROCE JÚNIOR, Delton. Erro Médico e o Direito. 2. ed. - São Paulo: Saraiva, 2002.

DINIZ, Maria Helena. Curso de Direito Civil Brasileiro. Vol. 7 - Responsabilidade Civil. 24. ed. São Paulo: Saraiva, 2009.

GIOSTRI, Hildegard Taggesell. Erro Médico à Luz da Jurisprudência Comentada. 2. ed. Curitiba: Juruá, 2009.

GOMES, Júlio Cézar Meirelles; FRANÇA, Genival Veloso de. Erro Médico. In: Iniciação à bioética / Sergio Ibiapina Ferreira Costa, Gabriel Oselka, Volnei Garrafa, coordenadores. Brasília: Conselho Federal de Medicina, 1998.

GOMES, Rui Kleber Costa. Responsabilidade civil do médico no código de defesa do consumidor. São Paulo: Pillares, 2004.

GONÇALVES, Carlos Roberto. Responsabilidade Civil, 5. ed. São Paulo: Saraiva, 1994. 
IGNÁCIO, Aline Letícia. Responsabilidade Civil decorrente de erro médico. In: Faculdades Integradas "Antônio Eufrásio de Toledo", Presidente Prudente/SP. 2003. Disponível em:

http://intertemas.unitoledo.br/revista/index.php/Juridica/article/viewFile/194/194. Acesso em: 18 ago. 2016.

KFOURI NETO, Miguel. Culpa Médica e ônus da Prova. São Paulo: Revista dos Tribunais, 2002.

\section{3.}

Responsabilidade Civil do Médico. 8. ed. São Paulo: Revista dos Tribunais,

LIMA, Fernando Gomes Correia. Erro Médico e Responsabilidade Civil. Brasília: Conselho Federal de Medicina, Conselho Regional de Medicina do Estado do Piauí, 2012.

SANTANA, Eduardo. Processos Judiciais contra médicos registram alta de 1600\%: 7 em cada cem profissionais da medicina respondem a processos. Jornal Tribuna Paraná. Publicado em: 08 abr.2014. Disponível em:

http://www.tribunapr.com.br/noticias/parana/processos-judiciais-contra-medicos-registramalta-de-1-600/. Acesso em: 24 out. 2016.

SANTOS, Marco Fridolin Sommer. A AIDS Sob a Perspectiva da Responsabilidade Civil. São Paulo: Saraiva, 1999, p.83.

SCHAEFER, Fernanda. Responsabilidade Civil do Médico e Erro de Diagnóstico. $1^{\mathrm{a}}$ ed. (ano 2002), 11. reimp. / Curitiba: Juruá, 2012.

SERPA LOPES, Miguel Maria de. Curso de Direito Civil: Fontes contratuais das obrigações. Responsabilidade Civil. 4. ed. Rio de Janeiro: Freitas Bastos, 1995.

STOCO, Rui. Tratado de responsabilidade civil: doutrina e jurisprudência. 7 ed. São Paulo: Revista dos Tribunais, 2007. 2011.

Tratado de Responsabilidade Civil. 8. ed. São Paulo: Editora Revista dos Tribunais, 